\title{
Taking the Guesswork Out of Curriculum Design: Learning to Engineer Explicit Grammar Curricula through the Analysis of Multiple Influences on the Acquisition Process
}

\author{
Andrew D. Schenck, Wonkyung Choi* \\ Department of Liberal Arts Education (LAEC), Ju Si-Gyeong College, \\ Pai Chai University, Daejeon, "South Korea \\ Email: Schenck@hotmail.com,wkchoi@pcu.ac.kr
}

Received June $21^{\text {st }}, 2012$; revised July $21^{\text {st }}, 2012$; accepted July $28^{\text {th }}, 2012$

\begin{abstract}
While a study by Goldschneider and DeKeyser (2005) was able to explain how factors such as phonological salience, frequency, morphological regularity, semantic complexity, and syntactic complexity influence acquisition order, the examination of six similar morphological features provided only a limited perspective. The purpose of this study was to see if causal variables, both individually and cumulatively, could be used to predict acquisition orders with more highly disparate morphological and syntactic features. Results of Spearman rank calculations revealed that the integration of causal factors yielded the highest correlation to both the Processability Theory $\left(r_{\mathrm{s}}=0.821 ; \mathrm{p}=0.007\right)$ and Natural Order Hypothesis $\left(r_{\mathrm{s}}=0.529 ; \mathrm{p}=0.143\right)$, suggesting that these factors have a synergistic influence on morphosyntactic development. Methods to predict the acquisition of both syntactic and morphological features are suggested, along with an empirically-based method to guide explicit grammar instruction.
\end{abstract}

Keywords: Explicit Grammar Instruction; Processability Theory; Natural Order Hypothesis; Acquisition Order; Frequency; Morphosyntactic Complexity

\section{Introduction}

Although explicit grammar instruction has been extensively investigated (Norris \& Ortega, 2000; Spada \& Tomita, 2010), a debate concerning its efficacy persists today. Some researchers argue that the effects of this instruction are ephemeral and of limited use in production tasks (Tode, 2007; Truscott \& Hsu, 2008), while others purport that it can bring about significant improvement (Ellis, Sheen, Murakami, \& Takashima, 2008; Norris \& Ortega, 2000; Spada \& Tomita, 2010).

In reality, the debate concerning explicit grammar instruction is being fueled by a deficiency in theoretical understanding of the second language acquisition process. Although several historical studies document a clear sequence of acquisition for L2 learners (Cook, 2001; De Villiers \& De Villiers, 1973; Dulay \& Burt, 1974; Dulay, Burt, \& Krashen, 1982; Krashen \& Terrell, 1983; Pienemann, 1999, 2005; Simmons, 2001), they have failed to provide a holistic perspective from which effective explicit grammar curricula can be created. Three main methodological flaws have prevented the development of a holistic perspective that can be applied to practice.

First, historical studies have not examined acquisition orders large enough to effectively guide the sequencing of explicit grammar lessons. Rather than extending the limited order of 14 morphemes first discovered by Brown (1973) in the 1970s, successive studies continued to examine only a few morphosyntactic features in isolation, numbering from 10 to 14 (De Villiers \& De Villiers, 1973; Dulay \& Burt, 1974, 1975; Krashen \& Terrell, 1983; Johnston, 1985, 1994; Pienemann, 1999, 2005). These designs have had only limited utility, because they illuminate

${ }^{*}$ Corresponding author. only a small facet of a more complex acquisition process. In addition, each research project used different participants at disparate developmental levels, meaning that results, which contained different morphosyntactic features, could not be cross-referenced to provide a more holistic perspective.

Secondly, morphosyntactic features have not been categorized in an organized way, obfuscating results that could be used to improve instruction (Cook, 1993). A study by Dulay and Burt (1975), for example, separately examined two allomorphs for the plural morpheme (-s/-es) while allomorphs for both the copula and progressive auxiliary ('s/is) were placed within a single category. Other research studies, in contrast, included the plural $-s$ and long plural -es within one category and separated the contractible copula and auxiliary features from non-contracted forms (Dulay, Burt, \& Krashen, 1982). Because researchers have not categorized morphosyntactic features consistently, educators have had difficulty determining how these features should be integrated within one curriculum.

Finally, historical acquisition order research has not accurately defined causes of the sequence of acquisition, inhibiting the ability of educators and curriculum designers to predict how modification of explicit grammar curricula will affect performance. Cook (1993) commented that:

The order of acquisition is not the reason behind errors; it is a generalisation about errors which still lacks a reason. To me, such remarks are more like Newton announcing that apples fall to the ground than the discovery of the theory of gravity - describing one limited instance rather than explaining it (p. 44).

Just as this statement implies, the lack of an explanation for 
acquisition order has severely limited the significance of the findings. SLA researchers must understand why the phenomenon occurs, since manipulation of a cause is a necessary precursor to the engineering of a desired effect. To date, attempts to adapt acquisition order to practice have focused on the acquisition order phenomenon itself, rather than its underlying causes. In the 1980s, for example, Pienemann $(1995,1999)$ attempted to explain what morphosyntactic features were "teachable", based upon the developmental level of the ESL learner. Later, Hill and Flynn (2008) also developed a set of questions that were designed to elicit language found at different SLA stages, from the Preproduction Stage to the Advanced Stage. Ultimately, for acquisition order to be useful in practice, educators must know both the causes of the phenomenon, and the means to manipulate these causes to obtain a desired result.

Due to the limited size of acquisition orders, inconsistencies with the classification of grammatical features, and undefined causes of the acquisition process, past research of morphosyntactic development has been of limited use to educators and curriculum designers. Such problems have precluded the ability of educators to accurately predict how changes to explicit grammar curricula will influence the acquisition process. As a consequence, educators are now forced to rely on intuition when designing explicit grammar curricula, which explains why such curricula do not appear to parallel known research of morphosyntactic development (Biber \& Reppen, 2002).

\section{Literature Review}

Brown (1973) was one of the first researchers to examine the similarities of morphosyntactic development among different language learners. In the 1970 s, he discovered an "invariant" order of acquisition for children learning English as their L1. Following this discovery, researchers such as Dulay and Burt (1974, 1975) also discovered that children learning English as a second language acquire morphosyntactic features in a distinct order. Krashen and Terrell (1983), through the synthesis of past ESL studies, developed a 4 stage hierarchy of morphosyntactic development termed the Natural Order (Table 1). According to this order, progressive, copula, and plural morphemes were acquired in early stages, while past tenses, the third person singular, and possessive morphemes were acquired late in the acquisition process.

\section{The Processability Theory}

Following the discovery of morphological sequences of acquisition, both Johnston $(1985,1994)$ and Pienemann (1999, 2005) discovered a sequential list of morphosyntactic development referred to as the Processability Model. Like prior research of morphological sequences, grammatical elements of this model appeared to be universal, regardless of factors such as age or linguistic background (Pienemann, 1999, 2005; Cook, 2001). Unlike prior research of morphological features, however, the Processability Model included several syntactic features involved in the construction of questions and complex clauses.

Grammatical features were organized into six discreet stages, which revealed the development of speech from small phrases to complex sentences (Table 2). The first two stages describe the development of basic SVO syntax and individual phrases. In stage two, learners begin to organize words into SVO sentences
Table 1.

Stages of the natural order.

\begin{tabular}{cc}
\hline Stage & $\begin{array}{c}\text { Natural Order Hypothesis } \\
\text { Krashen \& Terrell (1983) }\end{array}$ \\
\hline \multirow{2}{*}{1} & Progressive (-ing) \\
& Plural (-s) \\
Copula (is) \\
2 & Singular Auxiliary (is) \\
& Article (a, the) \\
3 & Past Irregular \\
& Regular Past \\
4 & Third Person Singular $(-s)$ \\
\end{tabular}

Table 2.

Stages of the processability model.

\begin{tabular}{cc}
\hline Stage & Processability Model \\
& Pienemann (1999) \& Johnston (1985) \\
\hline 1 & Single Words \\
SVO Sentences \\
Plural (-s) \\
Negative + Verb \\
Do-Fronting \\
Topicalization \\
Adverb-Fronting \\
3 & Yes/No Question Inversion \\
& Particle Verb Separation \\
& Wh-copula Question Inversion \\
& Wh-auxiliary Question Inversion \\
4 & Third Person Singular (-s) \\
& Cancel Inversion \\
\hline
\end{tabular}

and use morphosyntactic features (e.g., plural -s) to build more complex phrases (Mitchell \& Myles, 2004).

Stage three is marked by the use of adverbials, do-fronting, topicalization, and negation. During this stage, grammatical features are simply moved to the front of a phrase or sentence. The do auxiliary verb, for example, is moved to the front of the sentence to form a question, as in the example, Do you like it? This movement, referred as do-fronting, is posited to occur without any conjugation of the auxiliary do verb. Topical noun phrases are also moved to the head of a sentence in a process called topicalization. Learners begin to use sentences such as That, I like. Finally, sentences are negated by putting the word no in front of a verb phrase. The sentence I no like that is an illustration of this process (Pienemann, 1999, 2005).

At stage four, morphological development requires manipulation of multiple phrases (Pienemann, 1999). Learners begin to change phrasal elements within a sentence, through inverting the subject and verb in yes/no (e.g., Has he read the book?) and copula (e.g., What is he doing?) questions. Students also manipulate phrases by embedding an accusative nominal phrase within a separable particle verb, as in the following example, $I$ put the book in the bookcase (Cook, 2001). During stage five, learners continue to master use of multiple phrases through the inversion of auxiliary verbs within Wh-questions and inflection of the third-person singular morpheme (Pienemann, 1999, 2005).

During stage six, learners begin to use larger subordinate clauses to change elements on a sentential level. They use cancel inversion, which refers to the absence of inversion found in 
the subordinate clause of an embedded question (e.g., Could you tell me where the bank is?). This represents the final stage of the Processability Model (Cook, 2001; Pienemann, 2005).

Unlike previous models, which included only morphological features, the Processability Model included more complex syntactic features that modify phrases (question inversion) and larger clauses (cancel inversion). Recently, even more complex connectives (e.g., but, and, then, when, because), which modify elements on a sentential level, have been found to emerge in a distinct order (Evers-Vermeul \& Sanders, 2009).

\section{Causes of Acquisition Order}

Although each morphosyntactic sequence was insightful, researchers could not agree about causes of the phenomenon, which limited the degree to which it could be utilized or engineered to improve instruction (Cook, 1993). In the early 1970s, when research of morphological sequences first began, Brown (1973) proposed several causes for the acquisition phenomenon, namely, semantic complexity, syntactic complexity, and input frequency. This sparked a debate over the validity of each individual factor, which served to obfuscate the interrelated nature of the multiple causes. While De Villiers and De Villiers (1973) agreed that syntax and semantic causes could explain the acquisition process, they concluded that frequency had no apparent role. Larsen-Freeman (1976), in contrast, posited that a signifycant correlation existed between acquisition order and frequency. Dulay and Burt (1974) downplayed the role of semantics, citing that L2 learners already possessed a complex semantic understanding through their L1, and, therefore, were not impeded by this factor. They, instead, explained acquisition as a product of the interaction between innate systems governing the development of syntax and the surrounding input.

In the 1980s, researchers such as Pienemann $(1999,2005)$ and Johnston $(1985,1994)$ posited that syntactic complexity determined the emergence of morphosyntactic features. First, learners use single words and lexical morphemes (e.g., the plural $-s$ ) that require no exchange of grammatical information. At higher stages of development, learners use grammatical features that require an exchange of information between phrases (e.g., third person singular) and clauses (e.g., cancel inversion) (Pienemann, 2005). As in previous studies of morphosyntactic acquisition, this theory is not consistently accurate. Recent research reveals, for example, that the model does not accurately predict the order of acquisition for each morphosyntactic feature with equal certainty (Dyson, 2009; Lee, 2006). While the model tends to correctly predict the sequence of syntactic features, it often fails to accurately predict when morphological features will be mastered (Dyson, 2009).

Following the exploration of causes such as syntax, semantics, and frequency, researchers began to realize that phonological characteristics of grammatical features also influence the acquisition process (Ellis, 2002). In the 1990s, research revealed that aspects of phonology influence the processing and interpretation of linguistic features (Saffran, Aslin, \& Newport, 1996). A follow-up study also revealed that young learners are sensitive to syllable sequences, further suggesting that phonological characteristics of a grammatical feature may influence its interpretation and use (Pelucchi, Hay, \& Saffran, 2009). To date, there is a large research corpus which confirms the existence of a strong link between phonology and morphosyntactic development (Martohardjono, 1989; McCarthy, 2004; Gass \&
Selinker, 2008).

In the early 21 st century, new research emerged which integrated and analyzed known causes of the acquisition process to provide a more holistic perspective (Evers-Vermeul \& Sanders, 2009; Goldschneider \& DeKeyser, 2005; Rowland, Pine, Lieven, \& Theakston, 2003). Although such research studies partially explained the order of acquisition through collective analysis of phonological salience, frequency, morphological regularity, semantic complexity, and syntactic complexity, the limited coverage of grammatical features in each study was of little utility to educators (Evers-Vermeul \& Sanders, 2009; Goldschneider \& DeKeyser, 2005; Rowland, Pine, Lieven, \& Theakston, 2003). A study by Goldschneider and DeKeyser (2005), for example, was limited to only 6 morphological features (present progressive -ing; plural -s, possessive $-s$; articles $a$, an, the; $3^{\text {rd }}$ person singular $-s$; and regular past $-e d$ ). Three of the six features investigated were homophonic, bound morphemes (plural $-s$, possessive $-s ; 3^{\text {rd }}$ person singular $-s$ ), meaning that values for characteristics such as phonological salience, morphological regularity, and syntactic complexity were equal. Lexically acquired features and aspects of syntax (e.g., past irregular tense and question inversion), which have a large number of variants and a high degree of phonological salience, were not examined.

Although modern studies continue to investigate causal factors of acquisition, they largely avoid the search for universal grammatical relationships, in favor of designs which examine individual morphosyntactic features and their causes (Boss, 2008; Bettoni \& DiBiase, 2011; Chang, Kobayashi, \& Amano, 2009; Friedmann \& Costa, 2011; Maguire et al., 2010; Westergaard, 2009; Williams, 2010). As with prior studies of morphosyntactic acquisition, these studies do not facilitate development of a holistic perspective which is needed to guide the design of explicit grammar curricula. To address this limitation within past research, the current study was designed to examine a large number of highly disparate morphosyntactic features, such as those included in the Processability Theory and Natural Order Hypothesis.

\section{Research Problem}

Although some research studies have partially explained the order of acquisition through collective analysis of phonological salience, frequency, morphological regularity, semantic complexity, and syntactic complexity, the limited coverage of grammatical features is of little utility to educators (Evers-Vermeul \& Sanders, 2009; Goldschneider \& DeKeyser, 2005; Rowland, Pine, Lieven, \& Theakston, 2003). To expand the utility of former research and provide a guide for explicit grammar curricula, analysis of more highly disparate morphological and syntactic features contained in the Natural Order and Processability Model were analyzed. The following questions were posed:

1) Can values of phonological salience, frequency, morphological regularity, semantic complexity, and syntactic complexity for each morphosyntactic feature be used to predict orders of the Processability Theory and Natural Order Hypothesis (Krashen \& Terrell, 1983; Pienemann, 2005)?

2) Does the integration of causal variables (phonological salience, frequency, morphological regularity, semantic complexity, and syntactic complexity) for each morphosyntactic feature more accurately predict orders of the Processability Theory and Natural Order Hypothesis than consideration of individual causes 
alone (Krashen \& Terrell, 1983; Pienemann, 2005)?

Predictions of the acquisition process will help researchers and educators further understand how multiple causes influence morphosyntactic development. This understanding, subsequently, may be used to engineer curricula to hasten the acquisition process.

\section{Method}

To address research question one, which attempted to ascertain if individual causes had predictive validity, the nonparametric Spearman rank correlation formula was used to correlate values of phonological salience, frequency, morphological regularity, semantic complexity, and syntactic complexity to the rank orders of features contained within the Processability Model and Natural Order.

To address research question two, which attempted to ascertain if the integration of causes had a higher predictive validity, all causal variables were combined into one predicted acquisition order through four steps. First, values for semantic complexity, morphological alternations, and morphosyntactic complexity were made negative, since larger values may slow the acquisition process, while values for sonority and frequency, which may hasten acquisition when values are higher, remained positive. Second, all scores for phonological salience (sonority), morphological regularity (alternations), frequency, semantic complexity, and syntactic complexity were converted to z scores. Third, these $\mathrm{z}$ scores were averaged together to get one overall score for each morphosyntactic feature. Finally, the overall scores were ordered from the highest to the lowest value to construct the hypothesized acquisition order.

After the predicted acquisition order was calculated, it was correlated to the Natural Order and Processability Theories using the Spearman rank correlation formula. As in the correlation of individual causal factors, the limited number of features (16) and the predominance of ordinal data made this statistical formula the best choice.

\section{Operational Definition of Variables}

\section{Frequency}

Frequency refers to the number of times a morphosyntactic feature is present within input (Goldschneider \& DeKeyser, 2005). This ratio scale variable was obtained by using the Corpus of Contemporary American English (COCA) (Davies, 2008). This corpus, which contains 425 million words obtained from various sources of discourse in an American context, provided the means to search most morphosyntactic features contained within both the Processability Model and the Natural Order (See Appendix A for a list of corpus search strings and frequency values). In some cases, multiple search strings were needed for one grammar type. For Wh-questions, for example, single-word interrogative pronouns such as where or when had to be searched separately from those using two-word interrogative pronouns such as how long and how far. After multiple searches were executed, values were added to arrive at a total for the morphosyntactic feature.

Due to limitations of the corpus search engine, values for single words, SVO sentences, topicalization, and adverb-fronting could not be obtained. Since all of the components in search strings for these features appeared in the Corpus more than 10,000,000 times, the corpus search engine would not execute the searches. These features, therefore, had to be excluded from the investigation.

Determining frequency for negation from the Processability Model was difficult because it is an interlanguage feature. Pienemann (2005) defines negation as "an interlanguage form of negation where a lexically invariable form of a negator is used in preverbal position" (p. 19). According to this definition, invariable negation words no and not were included in the search to obtain a value for frequency.

\section{Morphosyntactic Alternation}

Morphosyntactic alternation is a ratio scale variable that refers to the number of different forms a grammatical feature may take. For morphological features, it was assessed by calculating the number of allomorphs. The plural -s morpheme, for example, which has three allomorphs, s, z, and Iz (used with nouns such as books, pens, and cages, respectively), was assigned a variability value of 3 . While this method of calculation mirrored that used within the study by Goldschneider and Deyser (2005), some modifications were made to increase accucy. The indefinite articles, $a$ and $a n$, for example, were exnded from two (e and æn) to four allomorphs (e and æn; ə and ən) because of the common use of both phonological variants within everyday speech. To estimate the total number of altertions for highly variable features such as the past irregular tense and separable phrasal verb, lists of these features from a comn English textbook were tallied (Master, 1996).

Variability for syntactic features was calculated by separateing the words within each syntactic feature into discreet categories and multiplying the total number of variants in each category to get a final estimate of alternations. Wh-auxiliary questions, such as those defined by Pienemann (1999), for example, were separated into three categories: interrogative, auxiliary verb, and subject pronoun (See Table B1 in Appendix B). Although subject pronouns cannot account for all subjects that may be used within questions, research of the Corpus of Contemporary American English (COCA) indicates that such pronouns account for more than $90 \%$ of the subjects used within question inversion and, thus, have been used to represent the subject category (Davies, 2008). The word lists for each category were obtained from Systems in English Grammar by Master (1996). The total number of variants in each category was then multiplied to estimate the total number of forms that could occur. Morphosyntactic variation for Wh-auxiliary questions, for example, was calculated by multiplying the number of interrogatives (11) by the number of auxiliary verbs (18) and the number of subject pronouns (7) for a total of 1386 alternations. Do-fronting, which requires one non-conjugated do verb, was calculated by multiplying 1 (Auxiliary do) by 7 (Subject pronouns), for a total number of 7 alternations.

\section{Phonological Salience}

Phonological salience refers to the ease with which a morphosyntactic feature can be heard (Goldschneider \& DeKeyser, 2005). This ratio scale variable was calculated by determining only the feature's sonority, which is the degree to which the vocal tract is open during articulation (Yavas, 2010). For this study, two scales by Laver (1994) and Hogg and McCully (1987) were integrated to provide the most comprehensive scale for analysis (See Table B2 in Appendix B). The sonority value for each morphosyntactic feature was calculated in two steps. First, the phones (distinct units of sound) of each variant of a 
morphosyntactic feature were added using the sonority scale. Second, the resulting values for each variant were added, and then divided by the total number of variants to get an average sonority value. The resulting value was used to represent the phonological salience of the target feature.

Although the number of phones and syllabicity were also included in the calculation of phonological salience by Goldschneider and DeKeyser (2005), only the sonority value was used within this study. This is because the number of phones and syllabicity are both reflected in the calculation of the sonority value. Morphemes with a larger number syllables, for example, have a higher sonority score (the vocal tract is open more when vowels of a syllable are produced).

\section{Semantic Complexity}

Semantic complexity is a ratio scale variable that refers to the total number of meanings conveyed by a morphosyntactic feature (Goldschneider \& DeKeyser, 2005). To calculate semantic complexity, the number of meanings conveyed by each grammatical structure were added using the method devised by Brown (1973) (See Table C1 in Appendix C). New meanings were also assigned to morphosyntactic features not described by Brown. Interrogatives, for example, were assigned the semantic designation question. In addition to earlierness, future was added to cover any features that have a future meaning. Finally, attributes were added to articles to better explain their semantic complexity. As pointed out by Goldschneider and DeKeyser (2005), the nonspecific attribute is far too simplistic to explain article use in its entirety. Therefore, in addition to the specific-nonspecific attribute, the distinction between common and proper nouns, mass and count nouns, and use for generic statements were included, for a total semantic complexity value of four.

\section{Morphosyntactic Complexity}

Morphosyntactic complexity refers to the degree of difficulty learners have acquiring a new grammatical feature. To rate each feature, a categorization system based upon an ordinal scale ranging from 1 (the least complex) to 6 (the most complex) was devised. The scale is based on the Processability Model, which suggests that less complex intra-phrasal aspects of morphology are acquired first, followed by more complex inter-phrasal and inter-sentential aspects of syntax (Pienemann, 1999). As in the study by Goldschneider and DeKeyser (2005), intraphrasal morphological features were further divided into lexical/functional categories, which were then subdivided into the free/bound categories (Zobl \& Liceras, 1994). Syntactic features, which re- ceived higher scores, were divided into inter-phrasal and inter-sentential categories to account for the complexity of information exchange between constituents such as phrases (e.g., particle separation and question inversion) or clauses (e.g., cancel inversion) (Pienemann, 1999). According to Table C2 in Appendix $\mathrm{C}$, free lexical morphemes are hypothesized to be acquired first, while inter-phrasal features are thought to be acquired last.

\section{Results}

Correlations of individual causes (frequency, sonority, complexity, morphological alternations, and syntactic complexity) revealed several notable results (See Table 3).

Frequency was the only factor which was positively correlated, albeit insignificantly, to the Processability Model $\left(r_{\mathrm{s}}=\right.$ $0.547)$. The positive correlation may reflect the factor's tendency to hasten the acquisition process as its value increases. In contrast to frequency, all other causal factors had negative correlations. Both morphosyntactic complexity $\left(r_{\mathrm{s}}=-0.797\right)$ and morphosyntactic alternations $\left(r_{\mathrm{s}}=-0.673\right)$ were highly signifycant to the 0.05 probability level, suggesting that these two factors are influential in slowing the acquisition of features in the Processability Model. The negative value of semantic complexity $\left(r_{\mathrm{s}}=-0.650 ; \mathrm{p}=0.058\right)$, which was nearly significant to the 0.05 probability level, may also have a role in slowing the acquisition process. While negative correlation values for complexity and alternations can be understood without difficulty, the negative correlation for sonority cannot easily be explained.

In contrast to the correlations of the Processability Model, individual causes did not correlate highly to the Natural Order. The highest correlations, sonority $\left(r_{\mathrm{s}}=0.456\right)$ and frequency $\left(r_{\mathrm{s}}=\right.$ 0.477), were both positively correlated to the Natural Order, suggesting that these causes may accelerate the acquisition process as their values increase. Semantic complexity's small correlation value $\left(r_{\mathrm{s}}=0.107\right)$ suggests it has a weak, if any, link to the acquisition process.

After causal variables were integrated, an acquisition order was constructed (See Appendix D) and correlated to the Processability Model and the Natural Order. While individual causal variables partially correlated to features found in the Processability Model and Natural Order, the collective integration of factors into one predicted acquisition order yielded even stronger correlations (See Table 4).

Correlation of the predicted acquisition order to the Processability Model, $r_{\mathrm{s}}=0.821$, was significant to the .01 probability level. This correlation was higher than any of the individual causes alone, suggesting that causal variables have a synergistic

Table 3.

Correlations to the processability model and natural order.

\begin{tabular}{lcccccc}
\hline & & Semantic Complexity & Sonority & $\begin{array}{c}\text { Morpho-Syntactic } \\
\text { Complexity }\end{array}$ & $\begin{array}{c}\text { Frequency } \\
\text { Morpho-Syntactic } \\
\text { Alternations }\end{array}$ \\
\hline Processability Model & $r_{\mathrm{s}}$ & -0.654 & -0.612 & $-0.797^{\mathrm{a}}$ & 0.547 & $-0.673^{\mathrm{a}}$ \\
& $\mathrm{p}$ & 0.056 & 0.080 & 0.010 & 0.127 & 0.047 \\
& $\mathrm{~N}$ & 9 & 9 & 9 & 9 & 9 \\
Natural Order & $r_{\mathrm{s}}$ & 0.107 & 0.456 & -0.268 & 0.477 & -0.005 \\
& $\mathrm{p}$ & 0.785 & 0.218 & 0.485 & 0.195 & 0.991 \\
& $\mathrm{~N}$ & 9 & 9 & 9 & 9 & 9 \\
\hline
\end{tabular}


Table 4.

Correlations to the processability model and natural order.

\begin{tabular}{ccc}
\hline & & $\begin{array}{c}\text { Predicted Sequence of } \\
\text { Acquisition }\end{array}$ \\
\hline Processability Model & $r_{\mathrm{s}}$ & $0.821^{\mathrm{a}}$ \\
& $\mathrm{p}$ & 0.007 \\
Natural Order & $\mathrm{N}$ & 9 \\
& $r_{\mathrm{s}}$ & 0.511 \\
& $\mathrm{p}$ & 0.160 \\
& $\mathrm{~N}$ & 9 \\
\hline
\end{tabular}

influence on the acquisition process. Correlation to the Natural $\operatorname{Order}\left(r_{\mathrm{s}}=0.511 ; p=0.160\right)$, likewise, was higher than individual causal correlations, supporting the claim that individual causal variables are partial determinants of acquisition order.

Overall, the predicted sequence of acquisition was able to explain acquisition of features in the Processability Model much more effectively than those in the Natural Order. Analysis of the predicted acquisition order in Appendix D reveals that syntactic features, which are only represented in the Processability Model, closely mirror known stages of morphosyntactic development (Pienemann, 2005). Types of inversion (do, yes/no, Wh-copula, Wh-auxiliary, and cancel inversion) and phrasal verb separation, for example, all appear in the correct stages. In contrast to syntactic features, morphological features did not follow known patterns of development as closely. The third person singular morpheme (Processability Model: Stage 5), for example, emerged before Wh-copula inversion (Processability Model: Stage 4) in the predicted sequence of acquisition (Appendix D). Although features associated with the final stage of the Natural Order (past regular, possessive $-s$, and third person singular) appear correctly in the predicted sequence, features of the other stages do not. Features of stage one (plural -s, progressive -ing, and the copula), for example, emerge in the hypothesized acquisition order after the article and past irregular, which occur in stages two and three of the Natural Order, respectively.

Through review of the empirical data, the discrepancy between the prediction of syntactic and morphological features may be explained by two key types of outliers which skew the values of $\mathrm{z}$-scores, thereby lessening the predictive validity of the sequence. First, syntactic and lexical features have a great deal more alternations (e.g., cancel inversion) because there are multiple words and phrases included within the feature. The number of alternations for both lexical features (past irregular) and syntactic features (do-fronting, phrasal separation, and question inversion) ranged from 7 to 1386 alternations, whereas those for the morphological features ranged from 1 to 6 . Second, outliers for frequency appeared to skew the significance of differences between less frequent features. Values for the article $(35,098,329)$ and past irregular $(10,740,546)$ features were both confirmed to be outliers through frequency plots. The median value for frequency $(2,575,784)$ is more reflective of the overall distribution scores than the mean $(4,741,198)$, which has been skewed by the article and past irregular outliers.

By removing syntactic/lexical features and outliers of frequency, the accuracy of morphology increases (See Appendix E). In both the revised acquisition order for morphological features and the Natural Order, for example, plural -s, progressive -ing, and the copula emerge in the earliest part of the sequence, while the past regular, possessive $-s$, and third person singular emerge in the latter part of the sequence. Only the present progressive auxiliary, which had a higher value for semantic complexity, emerged in an unpredictable order within the last part of the hypothesized sequence. Through the removal of outliers, accuracy of the predicted sequence of morphological acquisition was increased to $r_{\mathrm{s}}=0.694(p=0.083)$.

\section{Discussion}

Although individual causes such as frequency, sonority, complexity, morphological alternations, and syntactic complexity partially explain morphosyntactic development, their integration serves as a stronger predictor of the acquisition process. Higher correlations between the predicted order of acquisition and the Processability Model and Natural Order suggest that multiple causal factors are concomitantly responsible for the sequences observed in historical studies. Because each causal factor may be partly responsible for the acquisition process, an approach to explicit instruction should utilize input and pedagogical techniques commensurate with causal characteristics of each target feature.

Since morphosyntactic development can be predicted through the synthesis of multiple causes, grammatical sequences such as those found in the Processability Model and Natural Order should no longer be explained away as the manifestation of an innate, mysterious force. Results of this study reveal that the acquisition process has concrete causes which can be both understood and modified to enhance instruction. The educator may now work to engineer explicit grammar instruction that hastens acquisition or promotes uniform development of morphosyntactic features. Given the method of calculation within this paper, however, features having outlying causal values can skew the significance of other more minute disparities between features. Syntactic (e.g., question inversion) and lexical features (e.g., past regular), for example, have large numbers of alternations and high sonority values, which skew key differences between less variable and less sonorant morphological features. To increase the accuracy of predictions, syntactic and lexical features should be separated from morphological features for calculation.

In order to apply predictions of acquisition to practice, the educator must develop a scale that describes appropriate instructional interventions for each grammatical feature. To illustrate how this may be accomplished, a 4-point scale was developed for the 16 morphosyntactic features analyzed within this study. Values for each causal variable were divided into quarters and assigned a scale value $(0 \%-25 \%=4 ; 26 \%-50 \%=3$; $51 \%-75 \%=2 ; 76 \%-100 \%=1)$. Ratings of 1 , which are assigned to higher causal values that may hasten the acquisition process, require little emphasis; ratings of 4 , in contrast, are assigned to lower causal values that may slow the acquisition process, suggesting they require more extensive curricular emphasis. Due to the aforementioned influences of syntactic and lexical outliers, ratings for syntactic/lexical and morphological features were calculated separately. After grammatical features were converted into the 4-point scale, causal variables of frequency, alternations, semantic complexity, morphosyntactic complexity, and sonority were paired with the corresponding instructional interventions respectively: input, pronunciation, visual images, grammar exercises, and listening exercises. The results were then compiled into Table 5 .

The values in Table 5 yield several insights as to how ex- 
plicit grammar instruction should be modified to hasten acquisition of selected features. First, highly sonorant features that have a listening rating of 1 , such as progressive -ing, should not receive extensive emphasis within listening input. Those having a listening rating of 2 , in contrast, such as the progressive auxiliary or copula, should appear twice as often in listening dialogues. Features with ratings of 3 and 4 require even more emphasis. They should appear in listening dialogues three to four times more often than those with a rating of 1 . According to Table 5, grammatical features with the lowest sonority, such as the past tenses, third person singular $-s$, possessive $-s$, plural $-s$, do questions, and yes/no questions, require the highest degree of emphasis within listening and verbal input to ensure acquisition.

Second, complex syntactic features such as cancel inversion, question inversion, and separable phrasal verbs, which have high ratings of 3 to 4 in the grammar exercise category, should be more highly emphasized through strategies such as focuson-form and written exercises that draw attention to the relationships between grammatical elements of a sentence. Complex morphemes (third person singular $-s$, possessive $-s$, plural $-s$, past regular, and progressive -ing) should also be substantially emphasized through exercises that highlight their grammatical function. Overall, morphosyntactic features with ratings of 2, 3 or 4 should respectively have 2, 3 or 4 times more grammar exercises than those which have a rating of 1 .

Third, features with high semantic complexity, such as the article, auxiliary questions, and cancel inversion, should be accompanied by the largest amounts of visual stimuli (e.g., pictures, videos, graphic organizers), thereby facilitating understanding of semantic relationships and sociolinguistic contexts. Video conversations in a supermarket, for example, could be used to show contexts in which the definite article is used (e.g., "Is this the new product you've been talking about?").

Fourth, features with a large number of alternations, such as questions, articles, the progressive auxiliary and copula, should be emphasized highly within explicit grammar curricula. Deliberate attempts should be made to infuse alternative forms into aural and written input. As with the categories for listening, grammar exercises, and visuals, features with larger pronunciation ratings should have a commensurate expansion of content.

Finally, features with the lowest frequency, such as cancel inversion, the progressive auxiliary, and the possessive $-s$, should be emphasized most extensively. Due to their rating, these features should appear approximately four times more often than those with a rating of 1 . If normal, rather than accelerated, acquisition of features is desired, frequencies commensurate with those found in native contexts can also be infused within the input.

As can be seen from the above recommendations, designing grammar instruction using a scale such as that featured in Table $\mathbf{5}$ is needed. Unlike other methods of curriculum design, which create uniform tasks for each grammatical feature via a onesize-fits-all paradigm, this new approach tailors the curriculum to each grammatical feature in a way that maximizes the acquisition process. Although Table 5 provides useful information for curriculum designers, it still has one major limitation. It is designed with the assumption that all causal variables equally influence the acquisition process. Results in this study suggest that factors such as sonority and frequency may have a larger influence on morphological features than other causal factors (See Table 3). This assertion is confirmed when only values of sonority and frequency are integrated and correlated for morphological features; the resulting correlation is the best predictor of the Natural Order, yielding a value that is highly significant $\left(r_{\mathrm{s}}=0.849 ; p=0.016\right)$.

While isolating the significance of causal factors is straightforward in some circumstances, similar correlations of causal factors to some morphosyntactic features complicate assessments of individual influences. Values for morphosyntactic alternations, sonority, and morphosyntactic complexity, for example, will become larger as syntactic features grow in size. This may explain why integrating semantic complexity, sonority, morphosyntactic alternations, and frequency, without the most significant causal factor of morphosyntactic complexity, also yields the same highly significant correlation to the Processability Model $\left(r_{\mathrm{s}}=0.821 ; p=0.007\right)$ obtained in Table 4 .

Table 5.

Guide for curriculum design.

\begin{tabular}{|c|c|c|c|c|c|}
\hline $\begin{array}{l}\text { Grammar } \\
\text { Type }\end{array}$ & $\begin{array}{c}\text { Input } \\
\text { (Frequency) }\end{array}$ & $\begin{array}{l}\text { Pronunciation } \\
\text { (Alternations) }\end{array}$ & $\begin{array}{c}\text { Visuals } \\
\text { (Semantic Complexity) }\end{array}$ & $\begin{array}{l}\text { Grammar Exercises } \\
\text { (Syntactic Complexity) }\end{array}$ & Listening (Sonority) \\
\hline 1. Progressive -ing & 2 & 1 & 2 & 3 & 1 \\
\hline 2. Progressive Auxiliary & 4 & 4 & 3 & 2 & 2 \\
\hline 3. Copula & 2 & 4 & 2 & 2 & 2 \\
\hline 4. Past Regular & 3 & 3 & 2 & 3 & 4 \\
\hline 5. Third Person Singular $-s$ & 2 & 3 & 2 & 4 & 3 \\
\hline 6. Plural -s & 1 & 3 & 2 & 3 & 3 \\
\hline 7. Possessive-s & 4 & 3 & 2 & 3 & 3 \\
\hline 8. Article & 1 & 4 & 4 & 1 & 2 \\
\hline 9. Negation & 2 & 1 & 2 & 1 & 1 \\
\hline 10. Past Irregular & 1 & 3 & 2 & 1 & 4 \\
\hline 11. Separable Phrasal Verb & 2 & 2 & 2 & 3 & 2 \\
\hline 12. Do-Questions & 3 & 1 & 2 & 3 & 3 \\
\hline 13. Wh-Copula Questions & 2 & 3 & 3 & 3 & 2 \\
\hline 14. Yes/No Questions & 1 & 2 & 4 & 3 & 3 \\
\hline 15. Wh-Auxiliary Questions & 3 & 4 & 4 & 3 & 1 \\
\hline 16. Cancel Inversion & 4 & 4 & 4 & 4 & 1 \\
\hline $1=$ low emphasis needed & $\begin{array}{c}2=\underset{\text { medium emphasis }}{\text { needed }} \\
\end{array}$ & $\begin{array}{l}3=\text { medium high } \\
\text { emphasis needed }\end{array}$ & $4=$ high emphasis needed & & \\
\hline
\end{tabular}




\section{Conclusion}

Historical studies of morphosyntactic acquisition order could not be pragmatically applied to education, since causes and associated effects on the acquisition process were not well known. Although more recent research has worked to identify how multiple causes interact to affect acquisition order, the small scope of this research has limited its utility. Results of the current study suggest that extending the scope of study by predicting the order of a larger number of morphosyntactic features can lead to a better understanding of the L2 acquisition process. This understanding, in turn, may be used to modify both ESL and EFL input in ways that promote the uniform acquisition of multiple morphosyntactic features.

Although this study provides useful information for curriculum designers, more study is needed to increase the effectiveness of explicit grammar curricula. First, more morphosyntactic features must be studied and combined into a comprehensive scale. Second, the disparities of predictive validity for each morphosyntactic feature must be further examined and refined. Finally, the degree to which each individual causal factor influences the acquisition process must be more concretely determined. Through examination of each limitation, educators can accurately predict how reforms will impact second language learners, thereby allowing explicit grammar curricula to be engineered that are highly effective. Methodological reform of curricula is particularly necessary in EFL contexts, where limited resources and input have been shown to negatively impact the acquisition process (Chen, 2007; Lee, 2005; Liao \& Fukuya, 2004).

\section{Acknowledgements}

I would like to express my special appreciation to Professor Wonkyung Choi for serving as a corresponding author on this project. I would also like to thank my wife Jinny, son Matt, and daughter Katie for their patience and understanding, without which I could not have completed this paper.

\section{REFERENCES}

Bettoni, C., \& Di Biase, B. (2011). Beyond canonical order: The acquisition of marked word orders in Italian as a second language. EUROSLA Yearbook, 11, 244-272. doi:10.1075/eurosla.11.13bet

Biber, D., \& Reppen, R. (2002). What does frequency have to do with grammar teaching? Studies in Second Language Acquisition, 24, 199208. doi:10.1017/S0272263102002048

Boss, B. (2008). Exploring the acquisition of German verb morphology by instructed learners. Australian Review of Applied Linguistics, 31, 14-41. doi:10.2104/aral0814

Brown, R. (1973). A first language. Cambridge, MA: Harvard University Press.

Chang, F., Kobayashi, T., \& Amano, S. (2009). Social factors in the acquisition of a new word order. First Language, 29, 427-445. doi:10.1177/0142723709105316

Chen, J. (2007). On how to solve the problem of the avoidance of phrasal verbs in the Chinese context. International Education Journal, 8, 348-353.

Cook, V. (1993). Linguistics and second language acquisition. New York, NY: Palgrave.

Cook, V. (2001). Second language learning and language teaching (3rd ed.). London: Arnold.

Davies, M. (2008). The corpus of contemporary American English: 425 million words, 1990-present. URL (last checked 18 March 2012). http://corpus.byu.edu/coca/
De Villiers, J., \& De Villiers, P. (1973). A cross-sectional study of the acquisition of grammatical morphemes in child speech. Journal of Psycholinguistic Research, 2, 267-278. doi:10.1007/BF01067106

Dulay, H. C., \& Burt, M. K. (1974). Natural sequences in child language acquisition. Language Learning, 24, 37-53. doi:10.1111/j.1467-1770.1974.tb00234.x

Dulay, H. C., \& Burt, M. K. (1975). A new approach to discovering universals of child second language acquisition. In D. Dato (Ed.), Developmental psycholinguistics (Monograph series on language and linguistics) (pp. 209-233). Washington DC: Georgetown University Press.

Dulay, H. C., Burt, M. K., \& Krashen, S. (1982). Language two. New York, NY: Oxford University Press.

Dyson, B. (2009). Processability theory and the role of morphology in English as a second language development: A longitudinal study. Second Language Research, 25, 355-376. doi: $10.1177 / 0267658309104578$

Ellis, N. (2002). Frequency effects in language processing: A review with implications for theories of implicit and explicit language acquisition. Studies in Second Language Acquisition, 24, 143-188. doi: $10.1017 / \mathrm{S} 0272263102002024$

Ellis, R., Sheen, Y., Murakami, M., \& Takashima, H. (2008). The effects of focused and unfocused written corrective feedback in an English as a foreign language context. System, 36, 353-371. doi:10.1016/j.system.2008.02.001

Evers-Vermeul, J., \& Sanders, T. (2009). The emergence of Dutch connectives; how cumulative cognitive complexity explains the order of acquisition. Journal of Child Language, 36, 829-854. doi:10.1017/S0305000908009227

Friedmann, N., \& Costa, J. (2011). Acquisition of SV and VS order in Hebrew, European Portuguese, Palestinian Arabic, and Spanish. Language Acquisition, 18, 1-38. doi:10.1080/10489223.2011.530507

Gass, S. M., \& Selinker, L. (2008). Second language acquisition: An introductory course (3rd ed.). New York, NY: Routledge.

Goldschneider, J., \& DeKeyser, R. (2005). Explaining the "natural order of L2 morpheme acquisition" in English: A meta-analysis of multiple determinants. Language Learning, 55, 27-77. doi:10.1111/j.0023-8333.205.00295.x

Hill, J. D., \& Flynn, K. (2008). Asking the right questions. Journal of Staff Development, 29, 46-52.

Hogg, R., \& McCully, C. (1987). Metrical phonology: A coursebook. Cambridge, MA: Cambridge University Press.

Johnston, M. (1985). Syntactic and morphological progressions in learner English. Canberra: Commonwealth Department of Immigration and Ethnic Affairs.

Johnston, M. (1994). Second language acquisition: A classroom perspective. Australian studies in language acquisition no. 1. Washington DC: ERIC Database.

Krashen, S. D., \& Terrell, T. D. (1983). The natural approach. New York: Alemany Press.

Larsen-Freeman, D. E. (1976). An explanation for the morpheme acquisition order of second language learners. Language Learning, 26, 125-134. doi:10.1111/j.1467-1770.1976.tb00264.x

Laver, J. (1994). Principles of phonetics. Cambridge: Cambridge University Press. doi:10.1017/CBO9781139166621

Lee, C. (2005). Different types of English to which Korean college students are exposed outside the class. Washington DC: ERIC Database.

Lee, J. (2006). Korean children's acquisition of English interrogatives. Korean Journal of English Language and Linguistics, 6, 637-653.

Liao, Y., \& Fukuya, Y. J. (2004). Avoidance of phrasal verbs: The case of Chinese learners of English. Language Learning, 54, 193-226. doi:10.1111/j.1467-9922.2004.00254.x

Maguire, M. J., Hirsh-Pasek, K., Golinkoff, R., Imai, M., Haryu, E., Vanegas, S., Okada, H., Pulverman, R., \& Sanchez-Davis, B. (2010). A developmental shift from similar to language-specific strategies in verb acquisition: A comparison of English, Spanish, and Japanese. Cognition, 114, 299-319. doi:10.1016/j.cognition.2009.10.002

Martohardjono, G. (1989). The sonority cycle in the acquisition of phonology. Washington DC: ERIC Database. 


\section{A. D. SCHENCK, W. CHOI}

Master, P. (1996). Systems in English grammar: An introduction for language teachers. Upper Saddle River, NJ: Prentice Hall Regents.

McCarthy, J. J. (2004). Optimality theory in phonology. Malden, MA: Blackwell Publishing.

Mitchell, R., \& Myles, F. (2004). Second language learning theories (2nd ed.). London: Hodder Arnold.

Norris, J. M., \& Ortega, L. (2000). Effectiveness of L2 instruction: A research synthesis and quantitative meta-analysis. Language Learning, 50, 417-528. doi:10.1111/0023-8333.00136

Pelucchi, B., Hay, J., \& Saffran, J. (2009). Statistical learning in a natural language by 8 -month-old infants. Child Development, 80, 674685. doi:10.1111/j.1467-8624.2009.01290.x

Pienemann, M. (1999). Language processing and second-language development: Processability theory. Amsterdam: John Benjamins Publishing Company.

Pienemann, M. (2005). Cross-linguistic aspects of processability theory. Amsterdam: John Benjamins Publishing Company.

Rowland, C. F., Pine, J. M., Lieven, E. V. M., \& Theakston, A. L. (2003). Determinants of acquisition order in wh-questions: Re-evaluating the role of caregiver speech. Journal of Child Language, 30, 609-635. doi:10.1017/S0305000903005695

Saffran, J. R., Aslin, R. N., \& Newport, E. L. (1996). Statistical learning by 8-month-old infants. Science, 274, 1926-1928.
doi:10.1017/S0305000903005695

Simmons, G. V. (2001). The acquisition of the English determiner system: Sequence, order and transfer. Doctoral Thesis, Cambridge: ProQuest Dissertations and Theses Database.

Spada, N., \& Tomita, Y. (2010). Interactions between type of instructtion and type of language feature: A meta-analysis. Language Learning, 60, 263-308. doi:10.1111/j.1467-9922.2010.00562.x

Tode, T. (2007). Durability problems with explicit Instruction in an EFL context: The learning of the English copula "be" before and after the introduction of the auxiliary "be". Language Teaching Research, 11, 11-30. doi:10.1177/1362168806072398

Truscott, J., \& Hsu, Y. (2008). Error correction, revision, and learning. Journal of Second Language Writing, 17, 292-305.

doi:10.1016/j.jslw.2008.05.003

Westergaard, M. (2009). Usage-based vs. rule-based learning: The acquisition of word order in wh-questions in English and Norwegian. Journal of Child Language, 36, 1023-1051. doi:10.1017/S0305000909009349

Williams, J. N. (2010). Initial incidental acquisition of word order regularities: Is it just sequence learning? Language Learning, 60, 221244. doi:10.1111/j.1467-9922.2010.00607.x

Zobl, H., \& Liceras, J. (1994). Functional categories and acquisition orders. Language Learning, 44, 159-180. 


\section{Appendix A}

Table A1.

Grammar features, corpus search strings, and frequencies.

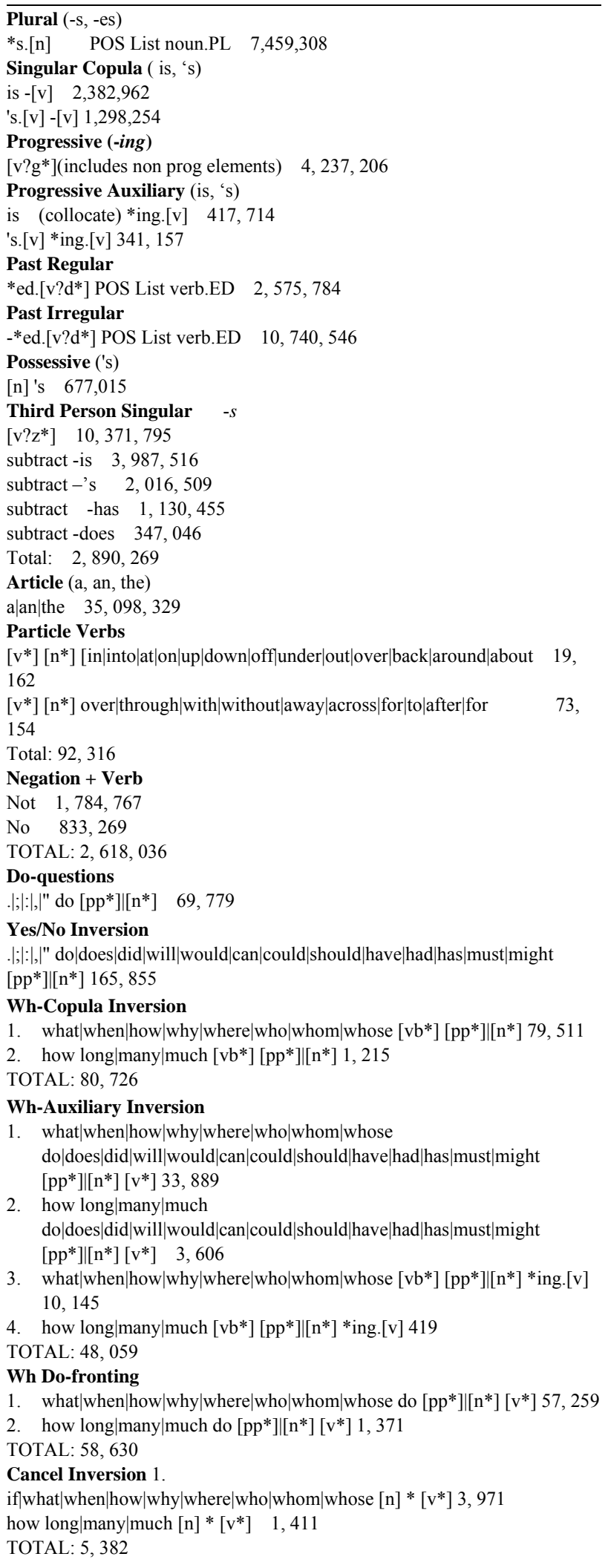

\section{Appendix B}

Table B1.

Categories of wh-aux question types.

\begin{tabular}{ccc}
\hline $\begin{array}{c}\text { Interrogatives } \\
\text { (Master, 1996: p. 141) }\end{array}$ & $\begin{array}{c}\text { Auxiliary } \\
\text { (Master, 1996: p. 12) }\end{array}$ & $\begin{array}{c}\text { Subject Pronouns } \\
\text { (Master, 1996: p. 149) }\end{array}$ \\
\hline What & Do & I \\
When & Does & You \\
Where & Did & He \\
Who & Will & She \\
Whom & Would & It \\
Whose & Can & They \\
Why & Could & We \\
How & Should & \\
How long & Have & \\
How many & Had & \\
How much & Has & \\
& Must & \\
& Might & \\
& Is (Progressive) \\
& Am (Progressive) \\
& Are (Progressive) \\
& Was (Progressive) \\
& Were (Progressive) \\
\hline
\end{tabular}

Table B2.

Sonority scale.

\begin{tabular}{ccc}
\hline Sound & Point Value & Examples \\
\hline Low Vowels & 12 & $\mathrm{a}, \mathfrak{}$ \\
Mid Vowels & 11 & $\mathrm{e}, \mathrm{o}$ \\
High Vowels & 10 & $\mathrm{i}, \mathrm{u}$ \\
Glides & 9 & $\mathrm{w}, \mathrm{y}$ \\
Flaps & 8 & $\mathrm{r}$ \\
Laterals & 7 & $\mathrm{l}$ \\
Nasals & 6 & $\mathrm{~m}, \mathrm{n}, \mathrm{g}$ \\
Voiced Fricative & 5 & $\mathrm{v}, \mathrm{z}, \mathrm{\partial}$ \\
Voiceless Fricative & 4 & $\mathrm{f}, \mathrm{s}, \theta, \mathrm{h}, \int$ \\
Affricate & 3 & $\mathrm{t} f, \mathrm{~d} 3$ \\
Voiced Stop & 2 & $\mathrm{~b}, \mathrm{~d}, \mathrm{~g}$ \\
Voiceless Stop & 1 & $\mathrm{p}, \mathrm{t}, \mathrm{k}$ \\
\hline
\end{tabular}

\section{Appendix C}

Table C1.

Semantic complexity calculation (Adapted from Brown, 1973).

\begin{tabular}{|c|c|c|}
\hline \multicolumn{2}{|r|}{ Morpheme } & Meanings \\
\hline 1. & Progressive -ing & Temporary duration \\
\hline 2. & $\begin{array}{l}\text { Plural } \\
\text {. }\end{array}$ & Number \\
\hline 3 . & Past Irregular & Earlierness \\
\hline 4. & Past Regular & Earlierness \\
\hline 5. & Possessive & Possession \\
\hline 6. & Present Copula & Number \\
\hline 7. & Article & $\begin{array}{l}\text { Specific-nonspecific; com- } \\
\text { mon/proper nouns; mass/count }\end{array}$ \\
\hline 8. & Third Person Singular $-s$ & Number \\
\hline 9. & $\begin{array}{l}\text { Present Progressive Auxil- } \\
\text { iary }\end{array}$ & Temporary duration; number \\
\hline 10. & Negation $(\mathrm{No} / \mathrm{Not})$ & Negation \\
\hline 11. & Do-fronting & Question \\
\hline 12. & Phrasal Verb & $\begin{array}{l}\text { Earlierness; number; future; tempo- } \\
\text { rary duration }\end{array}$ \\
\hline 13. & Wh Copula Question & $\begin{array}{l}\text { Question; earlierness; number; } \\
\text { future }\end{array}$ \\
\hline 14. & Yes/No Question & $\begin{array}{l}\text { Question; earlierness; number; } \\
\text { future; Temporary duration }\end{array}$ \\
\hline 15 . & Wh Auxiliary Question & $\begin{array}{l}\text { Question; earlierness; number; } \\
\text { future; Temporary duration }\end{array}$ \\
\hline 16. & Cancel Inversion & $\begin{array}{l}\text { Question; earlierness; number; } \\
\text { future; Temporary duration }\end{array}$ \\
\hline
\end{tabular}


Table C2.

Complexity for morphological and syntactic features.

\begin{tabular}{ll}
\hline Syntactic Categories & Points \\
\hline Lexical & \\
Free & 1 \\
Bound & 2 \\
Functional & \\
Free & 3 \\
Bound & 4 \\
Inter-phrasal & 5 \\
Inter-sentential & 6 \\
\hline
\end{tabular}

\section{Appendix D}

Table D1.

Predicted sequence of acquisition for all features.

\begin{tabular}{llc}
\hline \multicolumn{2}{l}{ Morphosyntactic Feature } & Z Score Value \\
\hline 1. & Past irregular & 0.82 \\
2. & Article & 0.68 \\
3. & Negation & 0.31 \\
4. & Is Copula Combined & 0.19 \\
5. & ING & 0.17 \\
6. & Plural -s & 0.16 \\
7. & Past regular & 0.03 \\
8. & Do questions & 0.02 \\
9. & Is Prog Combined & 0.01 \\
10. & Poss s & 0.01 \\
11. & Third person singular & -0.10 \\
12. & Wh Copula & -0.14 \\
13. & Phrasal verb separated & -0.25 \\
14. & Yes/no aux questions & -0.39 \\
15. & Wh aux questions & -0.69 \\
16. & Cancel Inversion & -0.86 \\
\hline
\end{tabular}

\section{Appendix E}

Table E1.

Morphological features (Syntactic, lexical, and frequency outliers removed).

\begin{tabular}{lc}
\hline Morphosyntactic Feature & Z Score Value \\
\hline 1. Negation & 0.83 \\
2. Progressive -ING & 0.75 \\
3. Plural -s & 0.28 \\
4. Is Copula & 0.05 \\
5. Past Regular & -0.31 \\
6. Possessive -s & -0.35 \\
7. Third Person Singular & -0.48 \\
8. Is Progressive & -0.78 \\
\hline
\end{tabular}

Table E2.

Correlations to the natural order (syntactic, lexical, and frequency outliers removed).

\begin{tabular}{ccc}
\hline & & Predicted Sequence of Acquisition \\
\hline \multirow{3}{*}{ Natural Order } & $r$ & 0.694 \\
& $\mathrm{p}$ & 0.083 \\
& $\mathrm{~N}$ & 7 \\
\hline
\end{tabular}

